\title{
An analytical solution for tidal propagation in the Yangtze Estuary, China
}

\author{
E. F. Zhang ${ }^{1}$, H. H. G. Savenije ${ }^{2}$, S. L. Chen ${ }^{1}$, and X. H. Mao ${ }^{3}$ \\ ${ }^{1}$ State Key Laboratory of Estuarine and Coastal Research, East China Normal University, Shanghai, China \\ ${ }^{2}$ Department of Water Management, Delft University of Technology, Delft, The Netherlands \\ ${ }^{3}$ Shanghai Hydrological Administration, Shanghai, China
}

Correspondence to: E. F. Zhang (efzhang@sklec.ecnu.edu.cn)

Received: 6 February 2012 - Published in Hydrol. Earth Syst. Sci. Discuss.: 20 February 2012

Revised: 19 August 2012 - Accepted: 20 August 2012 - Published: 18 September 2012

\begin{abstract}
An analytical model for tidal dynamics has been applied to the Yangtze Estuary for the first time, to describe the tidal propagation in this large and typically branched estuary with three-order branches and four outlets to the sea. This study shows that the analytical model developed for a single-channel estuary can also accurately describe the tidal dynamics in a branched estuary, particularly in the downstream part. Within the same estuary system, the North Branch and the South Branches have a distinct tidal behaviour: the former being amplified demonstrating a marine character and the latter being damped with a riverine character. The satisfactory results for the South Channel and the South Branch using both separate and combined topographies confirm that the branched estuary system functions as an entity. To further test these results, it is suggested to collect more accurate and dense bathymetric and tidal information.
\end{abstract}

\section{Introduction}

There exists a long tradition of analytical solutions for tidal dynamics in estuaries (Dronkers, 1964; Harleman, 1966; Ippen, 1966; Prandle and Rahman, 1980; Jay, 1991; Friedrichs and Madsen, 1992; Friedrichs and Aubrey, 1994; Lanzoni and Seminara, 1998; Savenije, 1998, 2001, 2005; Prandle, 2003; Horrevoets et al., 2004; Savenije and Veling, 2005; Savenije et al., 2008; Toffolon and Savenije, 2011). These solutions usually made assumptions to simplify or linearise the nonlinear set of equations. The cross-section of the estuary is generally assumed to be constant or gradually varying. The storage in the tidal flats adjacent to the channel, which affects tidal damping and tidal wave celerity, is generally neglected, except by Jay (1991), Friedrichs and Madsen (1992), Friedrichs and Aubrey (1994), and Savenije et al. (2008). The friction term is generally linearised, with a constant friction coefficient along the channel, except by Lanzoni and Seminara (1998), Savenije (1998, 2001, 2005), Savenije and Veling (2005), and Savenije et al. (2008). In Lanzoni and Seminara (1998)'s solution, although the nonlinear friction term was maintained, the spatial and temporal variation of the friction coefficient was ignored, while the channel axis was assumed to be straight, the bottom of the channel was fixed and horizontal, and the possible presence of tidal flats was ignored. Savenije $(1998,2001,2005)$ determined an analytical expression for tidal damping by subtracting high water (HW) and low water (LW) envelopes maintaining the nonlinear friction term, using an exponentially converging geometry allowing for bottom slope and tidal flats. For given geometry, friction, and tidal amplitude at the downstream boundary, Savenije et al. (2008) provided explicit analytical equations to compute the tidal damping, the wave celerity, the phase lag and the velocity amplitude along the estuary axis.

What all these analytical methods have in common is that they are derived for single-channel estuaries. Savenije's solution has been applied to about 11 estuaries worldwide such as the Schelde in the Netherlands, the Elbe in Germany, the Chao Phya in Thailand, the Maputo, Limpopo, Incomati and Pungue in Mozambique, and the Mekong in Vietnam (Savenije, 2001, 2005; Horrevoets et al., 2004; Savenije and Veling, 2005; Nguyen et al., 2007; Savenije et al., 2008). Among these, the Incomati and Mekong are branched estuaries, however, the branches were either lumped or considered 
one branch at a time (Savenije, 2001, 2005; Savenije and Veling, 2005; Nguyen et al., 2007). In this paper, we apply Savenije's solution to the Yangtze Estuary in China, a typical branched estuary with three-order branches and four outlets to the sea, to describe the tidal propagation for every branch and every reach of the estuary. The work is based on the assumption that the branches can be combined into a single channel. The model is calibrated and verified using field data, with good agreement between computed results and observations. The results suggest that the analytical model for a single-channel estuary can describe the tidal dynamics in a branched estuary system as well, and confirm that the estuary functions as an entity.

\section{Summary of the model}

The tidal dynamics in an alluvial estuary can be described by the following set of one-dimensional equations (Savenije et al., 2008):

$$
\frac{\partial U}{\partial t}+U \frac{\partial U}{\partial x}+g \frac{\partial z}{\partial x}+g \sigma+g \frac{U|U|}{C^{2} h}=0
$$

$r_{\mathrm{s}} \frac{\partial z}{\partial t}+U \frac{\partial z}{\partial x}+h \frac{\partial U}{\partial x}-\frac{h U}{a}=0$

where $U$ is the tidal flow velocity, $g$ is the acceleration due to gravity, $z$ is water level fluctuation, $\sigma=\partial\left(z_{\mathrm{b}}+\bar{h}\right) / \partial x-$ $h /(2 \rho) \partial \rho / \partial x$ includes the free surface residual slope and the density term, $z_{\mathrm{b}}$ is the bottom elevation, $\bar{h}$ is the tidal average water level, $h=z+\bar{h}$ is the water level, $\rho$ is water density, $C$ is Chezy's friction factor, $r_{\mathrm{s}}$ is the ratio between the storage width and the stream width, and $a$ is the area convergence length.

After scaling, Eqs. (1) and (2) can be rewritten as dimensionless equations:

$$
\begin{aligned}
& \frac{\partial U^{*}}{\partial t^{*}}+r_{\mathrm{s}} \zeta \mu \lambda U^{*} \frac{\partial U^{*}}{\partial x^{*}}+\frac{\lambda}{\mu} \frac{\partial z^{*}}{\partial x^{*}}+\frac{\lambda}{\zeta \mu} \sigma^{*}+\mu \chi \frac{U^{*}\left|U^{*}\right|}{C^{* 2} h^{*}}=0 \\
& \frac{\partial z^{*}}{\partial t^{*}}+\zeta \mu \lambda U^{*} \frac{\partial z^{*}}{\partial x^{*}}+\mu \lambda h^{*} \frac{\partial U^{*}}{\partial x^{*}}-\mu \gamma h^{*} U^{*}=0
\end{aligned}
$$

where the asterisk superscripts denote dimensionless variables $\left(U^{*}=U / v, t^{*}=t(2 \pi) / T, x^{*}=x(2 \pi) / L, z^{*}=z / \eta\right.$, $\sigma^{*}=\sigma L / \bar{h}, C^{*}=C / \sqrt{g / f}, h^{*}=h / \bar{h}, v$ is the amplitude of tidal velocity $U, T$ is tidal period, $L$ is wavelength, $\eta$ is the amplitude of water level fluctuation $z, f$ is dimensionless friction factor), $\zeta=\eta / \bar{h}$ is the dimensionless tidal amplitude. The dimensionless parameters $\chi, \gamma, \mu$ and $\lambda$ are friction number, estuary shape number, velocity number, and celerity number, respectively:

$$
\begin{aligned}
& \chi=r_{\mathrm{s}} f \frac{c_{0} \eta}{\omega \bar{h}^{2}} \\
& \gamma=\frac{c_{0}}{\omega a}
\end{aligned}
$$

$\mu=\frac{1}{r_{\mathrm{s}}} \frac{v \bar{h}}{\eta c_{0}}$

$\lambda=\frac{c_{0}}{c}$

where $\omega=2 \pi / T$ is tidal frequency, $c_{0}$ is the classical tidal wave celerity, $c$ is the actual tidal wave celerity for average depth. $c_{0}$ and $f$ can be calculated by means of the following equations:

$c_{0}=\sqrt{\frac{g \bar{h}}{r_{\mathrm{s}}}}$

$f=\frac{g}{K^{2} \bar{h}^{1 / 3}} /\left(1-\left(\frac{1.33 \eta}{\bar{h}}\right)^{2}\right)$

where $K=1 / n$ is the Manning-Strickler friction factor, $n$ is Manning's coefficient.

Based on 9 assumptions (see Appendix), Eqs. (1) and (2) can be written in the form of four implicit analytical equations, as described by Savenije (2005) and Savenije et al. (2008):

Phase lag equation $: \tan \varepsilon=\frac{\omega a}{c} /\left(1-\frac{a}{\eta} \frac{\mathrm{d} \eta}{\mathrm{d} x}\right)$

Scaling equation : $r_{\mathrm{s}} \frac{\eta}{\bar{h}}=\frac{v}{c} \frac{1}{\sin \varepsilon}$

Damping/Amplification equation :

$$
\frac{1}{\eta} \frac{\mathrm{d} \eta}{\mathrm{d} x}\left(\frac{1+\alpha}{\alpha}\right)=\frac{1}{a}-f \frac{v \sin \varepsilon}{\bar{h} c}
$$

Celerity equation :

$$
c^{2}=\frac{1}{r_{\mathrm{s}}} g \bar{h} /\left[1-\frac{\sin \varepsilon \cos \varepsilon}{(1+\alpha)}\left(\frac{c}{\omega a}-f \frac{v \sin \varepsilon}{\omega \bar{h}}\right)\right]=\frac{c_{0}^{2}}{1-D}
$$

where $\varepsilon$ is the phase lag between high water (HW) and high water slack (HWS) (or between low water (LW) and low water slack (LWS)), $\alpha=c v \sin \varepsilon /(g \eta)$ is a tidal Froude number, and $D$ is the damping term.

Making use of the dimensionless parameters Eqs. (5)-(8), defined above, and the damping number $\delta$, defined below, these four equations can be scaled resulting in four dimensionless equations:

Phase lag equation $: \tan \varepsilon=\frac{\lambda}{\gamma-\delta}$

Scaling equation : $\mu=\frac{\sin \varepsilon}{\lambda}=\frac{\cos \varepsilon}{\gamma-\delta}$

Damping/amplification equation :

$$
\delta=\frac{\mu^{2}}{\mu^{2}+1}\left(\gamma-\chi \mu^{2} \lambda^{2}\right)
$$


Celerity equation :

$$
\lambda^{2}=1-D=1-\delta \frac{\cos \varepsilon}{\mu}=1-\delta(\gamma-\delta)
$$

The damping number $\delta$ is defined as:

$\delta=\frac{1}{\eta} \frac{\mathrm{d} \eta}{\mathrm{d} x} \frac{c_{0}}{\omega}$

For more details about the derivation of these equations, we refer to the author comments posted in the interactive discussion forum of HESSD (http://www.hydrol-earth-syst-sci-discuss.net/9/2213/

2012/hessd-9-2213-2012-discussion.html).

Based on Eqs. (5-19), Savenije et al. (2008) derived explicit analytical solutions. For the so-called mixed wave where $\lambda^{2} \neq 0$, the damping number, celerity number, phase lag and velocity number can be described by the following relations.

$\delta=\frac{\gamma-\chi \mu^{2}}{2}$

$\lambda^{2}=\frac{\chi^{2} \mu^{4}-\gamma^{2}}{4}+1$

$\tan \varepsilon=\frac{\lambda}{\gamma-\delta}$

$\mu=\sqrt{\frac{1}{3 \chi}\left(m-\gamma+\frac{\gamma^{2}-6}{m}\right)}$

$m=\left[27 \chi+\left(9-\gamma^{2}\right) \gamma+3 \sqrt{3} \sqrt{27 \chi^{2}+2\left(9-\gamma^{2}\right) \gamma \chi+8-\gamma^{2}}\right]^{1 / 3}$

For the special case where $\lambda^{2}=0$ (the apparently standing wave), the following relations can be obtained (the subscript "s" represents the apparently standing wave):

$\mu_{\mathrm{s}}=\delta_{\mathrm{s}}=\frac{1}{2}\left(\gamma-\sqrt{\gamma^{2}-4}\right)$

$\lambda_{\mathrm{s}}=\varepsilon_{\mathrm{s}}=0$

The critical convergence $\gamma_{\mathrm{c}}$ is the transition point between these two wave types, given by:

$\gamma_{\mathrm{c}}=\frac{1}{3 \chi}\left[\frac{m_{1}}{2}-1+2 \frac{\left(12 \chi^{2}+1\right)}{m_{1}}\right]$

$m_{1}=\left[36 \chi^{2}\left(3 \chi^{2}+8\right)-8+12 \chi \sqrt{3} \sqrt{\left(\chi^{2}-2\right)^{2}\left(27 \chi^{2}-4\right)}\right]^{1 / 3}$

If $\gamma<\gamma_{\mathrm{c}}$ the solution for the mixed wave exists, while the solution for the apparently standing wave is for the case where $\gamma>\gamma_{\mathrm{c}}$.
For a longitudinal solution, the variable $\eta$ needs to be determined through integration of the damping number $\delta$. Based on Eq. (19), and using the tidal amplitude at the seaward boundary $\eta_{0}$, the damping number can be integrated stepwise. The two unknown parameters are: the ManningStrickler friction factor $K$ and the storage width ratio $r_{\mathrm{s}}$, which can be obtained by calibrating the computed results against measurements.

\section{The Yangtze Estuary}

The Yangtze Estuary is the part of the Yangtze River system downstream from Datong where the tidal limit is (Fig. 1). The estuary has an approximate length of $630 \mathrm{~km}$ and a mouth of about $90 \mathrm{~km}$ width. Downstream from Xuliujing, the estuary branches into the North Branch and the South Branch, forming Chongming Island. Further down, the South Branch branches into the North Channel and the South Channel, forming Changxing Island and Hengsha Island. Finally, the South Channel branches again into the North Passage and the South Passage forming Jiuduansha Island. As a result, the estuary has three-order branches and four outlets to the sea. Among this branched part, separate from the North Branch, the southern estuary system is called "the South Branches". The reach upstream from the junction of the North Branch and the South Branch to Datong is called "the Upper Reach".

\subsection{Shape of the Yangtze Estuary}

The geometry of the Yangtze Estuary can be described by exponential functions (Eqs. A1-A3), which correspond well with observations (squares, diamonds and triangles in Fig. 2). Good fits are obtained for both individual and combined channels. The Combined South Channel is the combination of the South Passage and North Passage $(0-33 \mathrm{~km})$, adding the South Channel (33-70 km). The Combined South Branch is the combination of the Combined South Channel and the North Channel (0-64 km), adding the South Branch $(64-113 \mathrm{~km})$. Upstream from $113 \mathrm{~km}$, following the South Branch, is the Upper Reach. The width and area of the combined channel are the sum of the widths and areas of corresponding separate channels. The depth of the combined channel is the ratio of the combined area to the combined width.

It can be seen that the combined channels such as $0-33 \mathrm{~km}$ of the Combined South Channel and 0-64 km of the Combined South Branch, appear as if they are a single channel, connecting well with the upper reach and demonstrating a regular topography. This suggests that morphologically the estuary system functions as a unity. Comparing the North Branch to the South Branches, we see clear differences in characteristics. In the North Branch, the width and depth both decrease upstream from the mouth. However, in the South Branches the width decreases mildly and there is a 


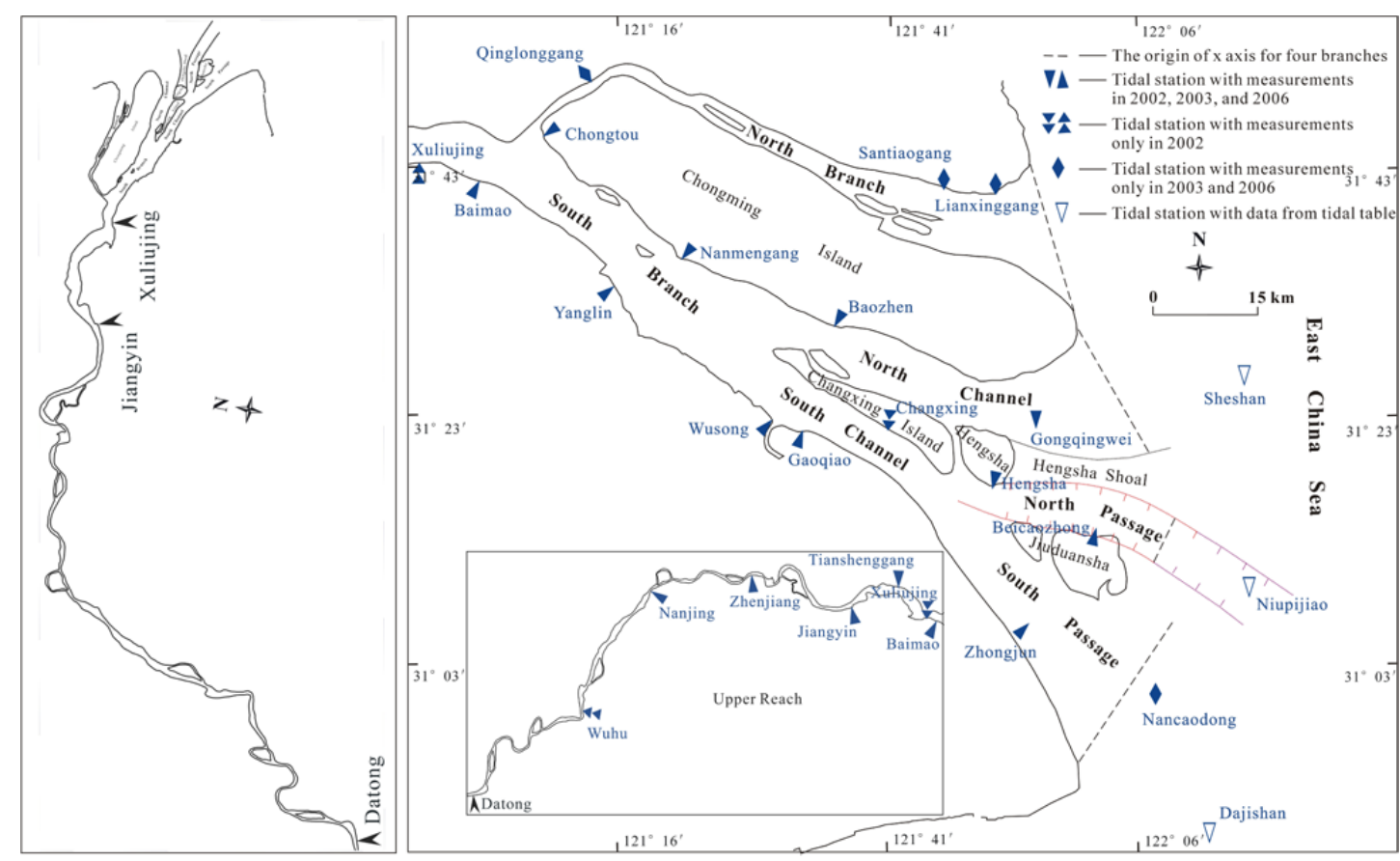

Fig. 1. The Yangtze Estuary.

slight increase of the depth. This is due to the marine character of the North Branch, which is a short estuary with a length close to the resonance length of the tide $\left(c_{0} T / 4\right)$, while the South Branches have a more riverine character, being long compared to the tidal wave length. Riverine estuaries generally have no bottom slope, whereas short estuaries do (Savenije, 2005).

\subsection{Hydrological conditions of the Yangtze Estuary}

The Yangtze Estuary experiences a mesoscale tide with a mean and maximum tidal range of $2.67 \mathrm{~m}$ and $4.62 \mathrm{~m}$, respectively, near the mouth at Zhongjun station (Shen et al., 2003). It has an irregular semidiurnal character. The average flood and ebb duration are 5 and $7.4 \mathrm{~h}$, respectively, at Zhongjun. On the whole, the tide gradually damps upstream from the mouth due to the increased impact of river discharge. The limit of the tidal flood current lies near Jiangyin (about $214 \mathrm{~km}$ from the estuary mouth), while the tidal limit is located near Datong, the location of which can vary with the river discharge.

The Yangtze Estuary receives a large amount of fresh water, with a mean annual discharge of $28310 \mathrm{~m}^{3} \mathrm{~s}^{-1}$ at Datong (1950-2009), and large seasonal and annual variation. Downstream from Xuliujing, the majority of the fresh water flows into the South Branch. Because the channel of the North Branch is almost perpendicular to the main channel, the freshwater inflow of the North Branch is very small: less than $1 \%$ and even $0.4 \%$ of the Yangtze River discharge in recent years (Chen and Chen, 2003; Yu et al., 2003; Tan and Wang, 2004; Zhang et al., 2011). Therefore, the South Branches deliver almost all fresh water from the Yangtze River to the sea.

The topography, river discharge, and tide interact and influence the characteristics of the channels. Assuming that the river discharge ratio of the North Branch is $1 \%$, and using the average river discharge of $16700 \mathrm{~m}^{3} \mathrm{~s}^{-1}$ during the dry season and $40000 \mathrm{~m}^{3} \mathrm{~s}^{-1}$ during the flood season at Datong station, the Canter-Cremers number $N\left(N=Q_{f} T / P_{\mathrm{t}}, T\right.$ is the tidal period, $P_{\mathrm{t}}$ is the tidal prism) during spring tide is about 0.0025 in the dry season, and 0.006 in the flood season for the North Branch, and 0.1 (dry season) and 0.24 (flood season) for the South Branches, respectively. This indicates that the North Branch is a marine well-mixed channel, and the South Branches have partially mixed character on the whole, which may become well-mixed during spring tide in the dry season (Zhang et al., 2011). Hence, the conditions of the Yangtze Estuary basically agree with the assumptions made in the Appendix. Although the Yangtze River has a large freshwater discharge, its tidal flow is an order of magnitude larger. Therefore, the large river discharge is not restrictive particularly during the dry season. 


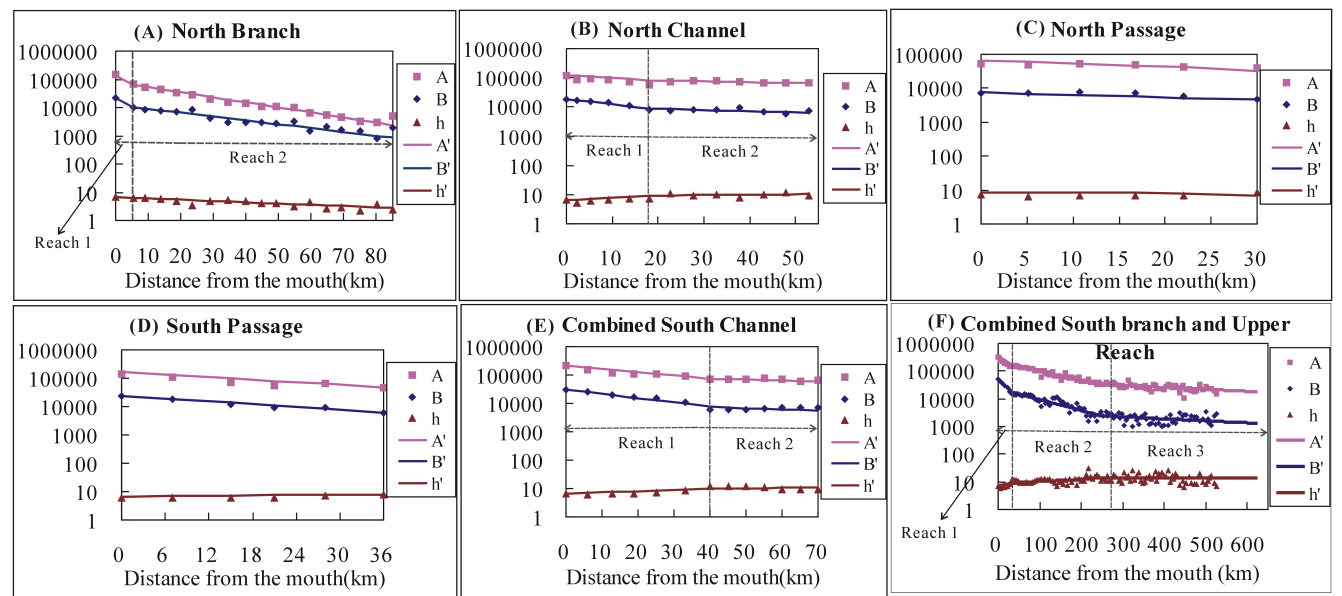

Fig. 2. Geometry of the Yangtze Estuary (Reach 1, 2, 3 represent the reaches of multi-reach channels, 1, 2, 3 are the reach number $i$ in Eqs. A1-A3).

\section{Calculation of tidal propagation for the Yangtze Estuary}

\subsection{Boundary conditions}

The domain of calculation is between estuary mouth and the tidal limit (Datong station), which are indicated in Fig. 1 by the dotted lines and triangle symbol, respectively. The landward boundary Datong is the last permanent hydrometric station with long discharge records in the main Yangtze River, with a mean annual discharge of $28310 \mathrm{~m}^{3} \mathrm{~s}^{-1}(1950-2009)$. The seaward boundary is the estuary mouth with a mean tidal range of about $2.8 \mathrm{~m}$, outside which the tide has a regular semidiurnal character.

\subsection{Approach}

Our previous research in the Yangtze Estuary demonstrated that the branched estuary system functions as an entity in terms of salt intrusion (Zhang et al., 2011). The same phenomenon was observed by Nguyen and Savenije (2006) and Nguyen et al. (2008) in the Mekong delta system. Based on this observation for salt intrusion, we assume that for tidal dynamics the branched estuary system will function as an entity as well. Hence, we consider both single branches and combined channels in the system: North Branch, North Channel, North Passage, South Passage, and the Combined South Channel and the Combined South Branch with Upper Reach.

For the single branches: the North Branch, the North Channel, the North Passage and the South Passage, computations are directly based on their individual topography using Eqs. (5)-(10), (19)-(26), starting from their mouths.

For the South Channel, computation continues from the junction of the North Passage and South Passage (junction 1), where the inputs of tidal amplitude and $t$ - LW and $t$ - HW are the weighted average of these two channels whose crosssectional areas at the junction are taken as the weight. For the South Branch, computation continues from the junction of the South Channel and the North Channel (junction 2). Similarly, the inputs are the weighted averages of these two branched channels. The distances from the mouth for the South Channel and South Branch in the model are measured based on the topographies of the Combined South Channel, and the Combined South Branch, respectively. At the junction of the South Branch and the North Branch, we do not consider the North Branch whose effect is considered to be small. The Upper Reach computation continues upstream directly from the South Branch.

In our approach, there are two modifications for the average depth $\bar{h}$. Firstly, the cross-sectional average depths between 130 and $250 \mathrm{~km}$ obtained by regression are corrected to better fit the measurements, because the depths obtained by regression (by dividing the regressed area by the regressed width) are much higher than the observed depths (Fig. 2f). Secondly, we adjust the tidal average depth for the different tidal amplitudes, as opposed to using the average depth at mean sea level. In this way, we take account of the varying average depth between different tidal amplitudes.

\subsection{Calibration}

The tidal observations of high water level (HW), low water level (LW) and their timing ( $t$-LW and $t$-HW) at 19 stations along the Yangtze Estuary on 21-22, 29-30 December 2006 (Fig. 1) have been used to calibrate the model. The ManningStrickler friction factor $K$ and storage width ratio $r_{\mathrm{s}}$ (Table 1) have been determined by calibrating the computed curves of longitudinal tidal damping/amplification and travel time of tidal wave against measurements. The computed results are presented in Fig. 3, with satisfactory fit to the measurements. Only the computed tidal travel time cannot fit nicely 


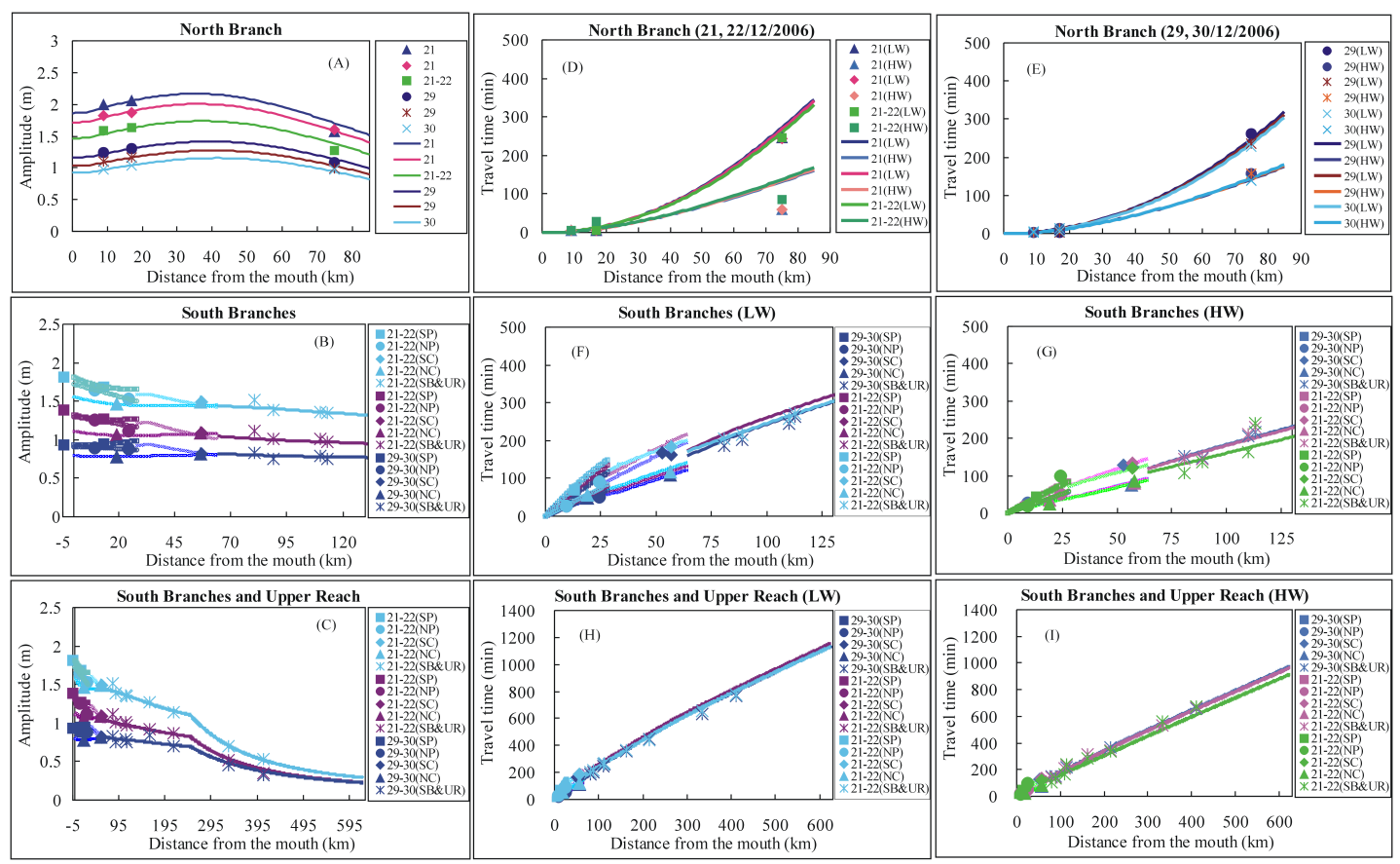

Fig. 3. Computed results (drawn lines) for the tidal amplitude (A-C) and travel time (D-I) along the Yangtze Estuary on 21-22, 2930 December 2006, compared to measurements (symbols).

to the measurements at Qinglonggang station $(75 \mathrm{~km})$ of the North Branch during spring tide particularly for high water (Fig. 3d). For the South Branches and Upper Reach, the computed travel time for low water is slightly higher than the observations. For better presentation and continuity between upper reach and lower channels, in plots $3 b, 3 c$ and 3f-i (Fig. 3) distances are measured from the estuary mouth for South Passage, North Passage, South Channel and North Channel, based on the topography of the Combined South Branch and Upper Reach. In the legend of these plots, the abbreviations SP, NP, SC, NC represent the South Passage, the North Passage, the South Channel and the North Channel, respectively, and SB\&UR stands for the South Branch $(64 \mathrm{~km}-113 \mathrm{~km})$ and Upper Reach. These abbreviations are used in the following figures as well.

The Manning's coefficient is an important parameter for the model. It is an index of the resistance to flow in a channel, which results from the interaction of many elements, such as particles of streambed material, bank irregularity, vegetation, channel alignment, bed forms, channel obstructions, converging or diverging streamlines, sediment load and surface waves (Limerinos, 1969). In estuaries, the Manning's coefficient $\mathrm{n}$ is considered to be between 0.033 and 0.04 for less turbid estuaries (Henderson, 1966; King and Wolanski, 1996). However, for turbid estuaries this value can be much smaller, such as the Fly River Estuary in Papua New Guinea and the South Alligator River Estuary in Australia with the values 0.015-0.02 (King and Wolanski, 1996), which may be due to the presence, in some areas, of fluid mud near the bot- tom, enabling the bulk of the flow to slip over muddy layers, thus, decreasing the bottom stress (Wolanski, et al., 1992).

In the Yangtze Estuary, the n-values for most channels we obtain are smaller than 0.02 with the minimum of 0.011 , i.e., the Manning-Strickler friction factor $K$ is $50-90$ (Table 1), which agree with the values $0.02-0.01$ used in some previous numerical-model research which usually covered the estuary downstream from Tianshenggang $(162 \mathrm{~km})$ or Jiangyin (214 km) (Wang, 1992; Zhou and Wu, 1994; Shi et al., 2003; Yu et al., 2007; Liu et al., 2010; Kong et al., 2010). The small $\mathrm{n}$-values are probably related to the turbid characteristic in the Yangtze Estuary as well, in which the maximum sediment concentration can reach $8 \mathrm{~kg} \mathrm{~m}^{-3}$ in the bottom layer of the turbidity maximum zone and there is the presence of fluid mud (Shen et al., 1995; Shen and Li, 2011). The smallest value in the North Channel (0.011) is in accordance with previous research by Wang et al. (1987) and corresponds with the observed amplification in this reach. The large value for the North Passage $(n=1 / K=0.03)$ may be due to its high water depth and long convergence length, resulting from dredging and bank fixation for shipping, which leads to more damping in this channel.

In addition, the storage width ratio $r_{\mathrm{s}}$ is an important parameter as well, particularly in a shallow mesotidal estuary. The tidal flats adjacent to the channel increase the friction, decrease wave celerity and enhance tidal damping. The values of $r_{\mathrm{s}}$ we obtained for the Yangtze Estuary (Table 1) basically agree with the assumption of the model $\left(r_{\mathrm{s}}<2\right)$. The large values for the channels near the mouth correspond with the large area of tidal flats. Because no data or reference on 
Table 1. Calibrated parameters $K$ and $r_{\mathrm{s}}$ of the Yangtze Estuary.

\begin{tabular}{|c|c|c|c|c|c|c|c|c|c|c|c|c|c|c|}
\hline & \multirow{2}{*}{ Parameter } & \multicolumn{2}{|c|}{$\begin{array}{l}\text { North } \\
\text { Branch }\end{array}$} & \multicolumn{2}{|c|}{$\begin{array}{l}\text { North } \\
\text { Channel }\end{array}$} & \multirow{2}{*}{$\begin{array}{l}\text { North } \\
\text { Passage }\end{array}$} & \multirow{2}{*}{$\begin{array}{c}\text { South } \\
\text { Passage }\end{array}$} & \multicolumn{2}{|c|}{$\begin{array}{c}\text { Combined } \\
\text { South Channel }\end{array}$} & \multicolumn{5}{|c|}{ Combined South Branch and Upper Reach } \\
\hline & & $\begin{array}{r}0-5 \\
\mathrm{~km}\end{array}$ & $\begin{array}{r}5-85 \\
\mathrm{~km}\end{array}$ & $\begin{array}{r}0-18 \\
\mathrm{~km}\end{array}$ & $\begin{array}{r}18-53 \\
\mathrm{~km}\end{array}$ & & & $\begin{array}{r}0-40 \\
\mathrm{~km}\end{array}$ & $\begin{array}{r}40-70 \\
\mathrm{~km}\end{array}$ & $\begin{array}{c}0-34 \\
\mathrm{~km}\end{array}$ & $\begin{array}{r}34-90 \\
\mathrm{~km}\end{array}$ & $\begin{array}{r}90-130 \\
\mathrm{~km}\end{array}$ & $\begin{array}{r}130-250 \\
\mathrm{~km}\end{array}$ & $\begin{array}{r}250-626 \\
\mathrm{~km}\end{array}$ \\
\hline \multirow{3}{*}{$r_{\mathrm{s}}$} & K & 50 & 50 & 55 & 90 & 33 & 50 & 45 & 50 & 50 & 71 & 60 & 55 & 30 \\
\hline & Spring tide & 1.1 & 1 & 2 & 1 & 1.1 & 2.1 & 1.72 & 1 & 1.85 & 1 & 1 & 1 & 1 \\
\hline & Neap tide & 1.1 & 1 & 2 & 1 & 1.1 & 2.1 & 1.72 & 1.7 & 1.9 & 1.45 & 1.1 & 1.1 & 1 \\
\hline
\end{tabular}

the storage width could be found, these results may have to be verified at a later stage.

\subsection{Validation}

The measurements on 18-19, 24-25 February 2003 at 19 stations along the Yangtze Estuary and the observations on 1-2, 8-9 March 2002 at 18 stations excluding the North Branch, have been used to validate the model and our approach, using the parameters in Table 1 . The calculated results fit the data well (Figs. 4 and 5). For the North Branch, the same deviation in the tidal travel time is obtained at Qinglonggang station $(75 \mathrm{~km})$ as in 2006 during spring tide particularly for high water (Figs. 4d and 3d). This may be due to the large difference in water depth between HW and LW at spring tide in this relatively shallow part of the estuary. The abnormal long travel time at Santiaogang $(17 \mathrm{~km})$ during neap tide in 2003 (Fig. 4e) is probably due to a data problem.

For the South Branches and Upper Reach, some computed tidal amplitudes for the upper reach particularly upstream from the location $250 \mathrm{~km}$ are not correct, considerably higher than observations during neap tide in 2003 and 2002 (Figs. 4c and 5b). Also a relatively bad fit of the tidal travel time occurs in this reach. These are likely due to the influence of the river discharge in this reach, or the changed topography which influences the roughness coefficient. For the South Passage, although there is only one tidal station, the computed results relate to the Nancaodong station $(-4.7 \mathrm{~km})$ very well (Figs. $3 \mathrm{~b}$ and $4 \mathrm{~b}$ ). For the lower reach of the North Channel, there is only one station available as well and there is no station near the mouth. However, there are three stations at sea: Sheshan, Niupijiao and Dajishan which are at similar positions outside the mouths of the North Channel, the North Passage and the South Passage, respectively (Fig. 1). Comparing these three stations, the tidal amplitude at Dajishan is usually slightly larger than at Niupijiao with a very small difference, whereas both are generally larger than at Sheshan (Fig. 6). These differences correspond with the differences between the three estuary mouths as presented in Figs. 3b, 4b and 5a.

\section{Discussion}

\subsection{Tidal damping and amplification}

Seeing from Figs. $3 \mathrm{a}-\mathrm{c}$ and $4 \mathrm{a}-\mathrm{c}$, in the Yangtze Estuary there are two clear differences between the North Branch and the South Branches. One is tidal damping or amplification. In the North Branch, the tidal wave is first amplified and then damped, while it is essentially damped along the South Branches, which agree with the common perception (Shen et al., 1988, 2003; Yang et al., 2001; Liu et al., 2006). However, among the South Branches there are some differences as well. In the South Passage, the tidal damping is less strong in the second half of the reach than in the first half. In the North Passage, the damping is the strongest. In the South Channel and the North Channel, slight amplification occurs before the inflection point and after the inflection point, respectively.

The other difference between the North Branch and the South Branches is that the tidal amplitude in the North Branch is larger than in the South Branches (Figs. 3a, b and $4 \mathrm{a}, \mathrm{b})$. Among the South Branches, the tidal amplitude is the highest near the mouth of the South Passage and the lowest near the mouth of the North Channel. One reason for this is the amplification in the North Branch and the damping in the South Branches. The other reason may be the largely different freshwater discharge into the channels, which also causes a difference in the salinity distribution between these channels (Zhang et al., 2011). Further upstream, between the South Channel and the North Channel, the tidal amplitudes in the two channels are equal at the intersection point, the location of Wusong in the South Channel and Baozhen in the North Channel. Before the intersection point the tidal amplitude is larger in the South Channel, and after which it is the reverse, which result from their tidal damping and amplification, respectively (Figs. 1, 3b, 4b, and 5a).

The tidal damping or amplification is the result of the imbalance between the topographic convergence and friction. If convergence is stronger than friction the wave is amplified, if friction is stronger than convergence the wave is damped (Langbein, 1963; Dyer, 1973; Jay, 1991; Friedrichs and Aubrey, 1994; Savenije, 1998, 2005). The amplification in the North Branch agrees with strong convergence. The amplification before the inflection point in the South Channel results from the funneling effect at the junction of the North 


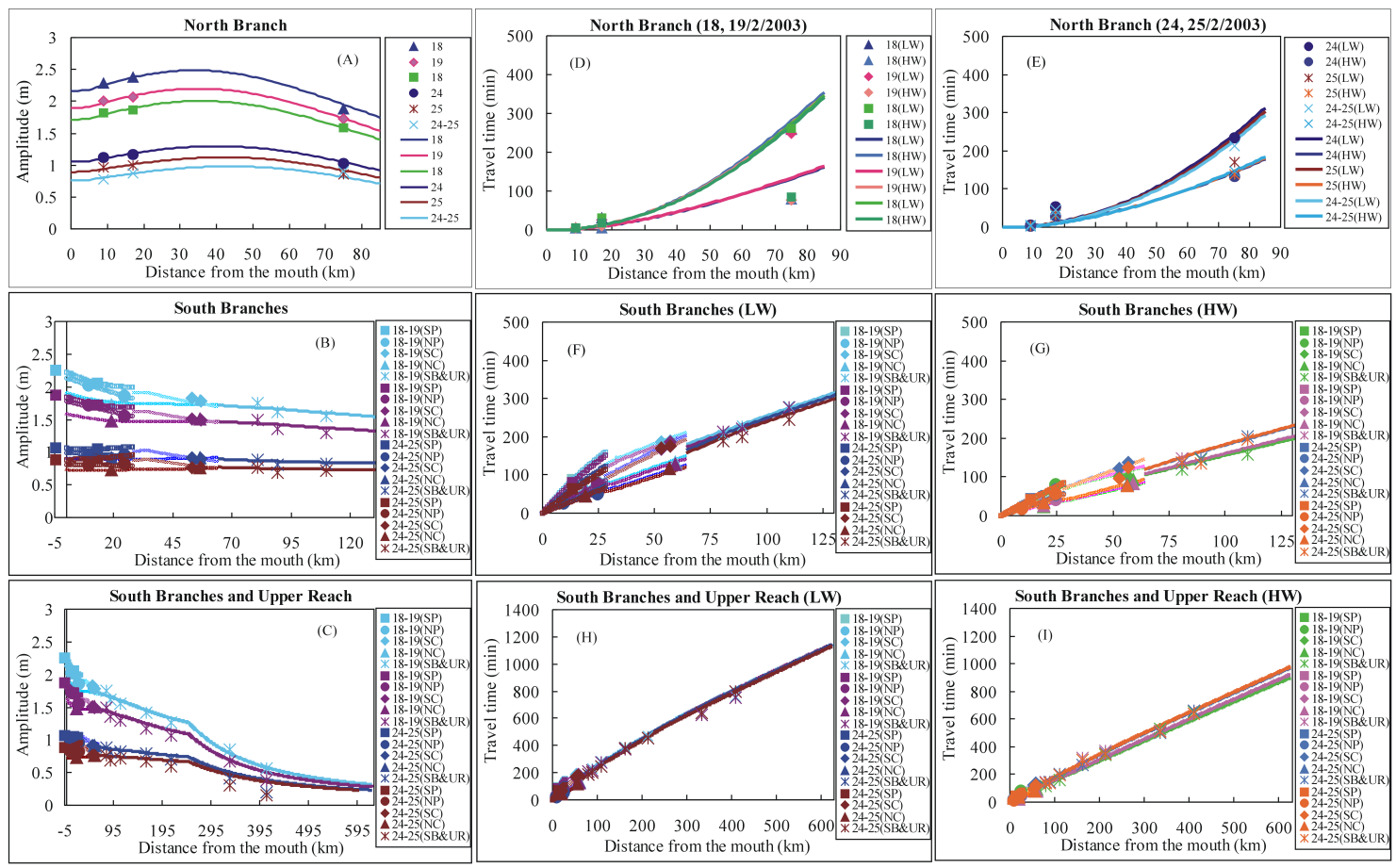

Fig. 4. Computed results (drawn lines) for the tidal amplitude (A-C) and travel time (D-I) along the Yangtze Estuary on 18-19, 2425 February 2003, compared to observations (symbols).

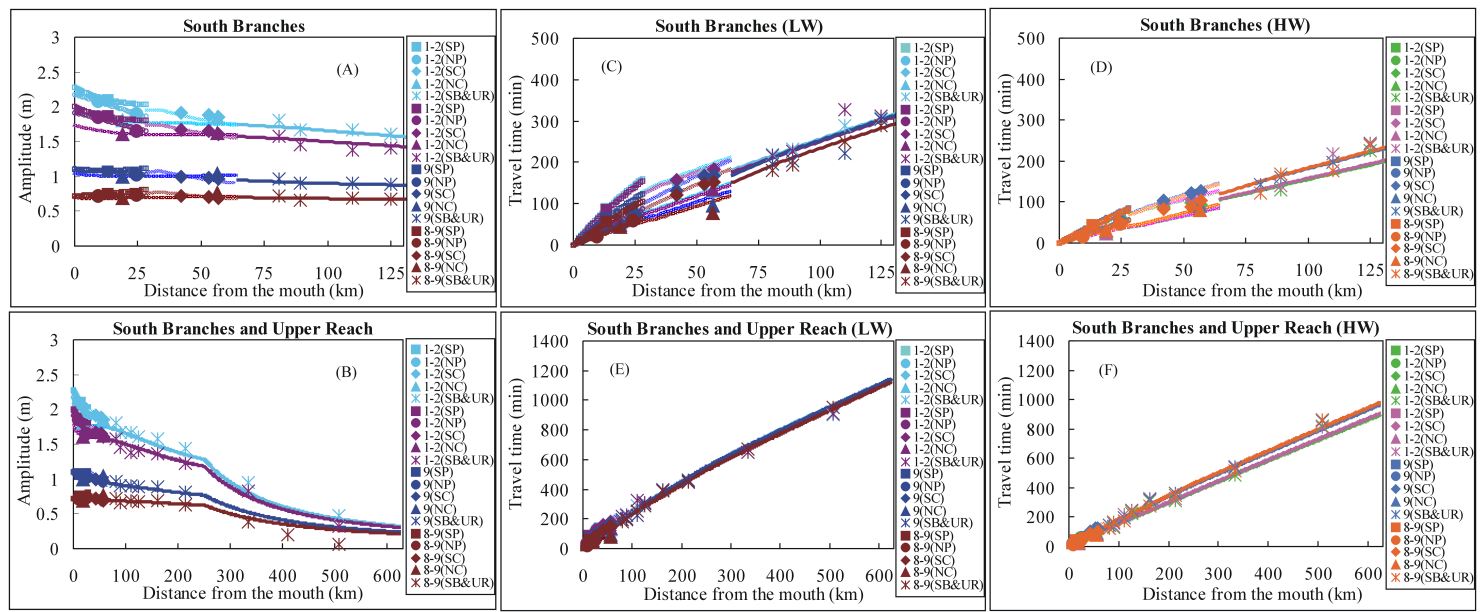

Fig. 5. Computed results (drawn lines) for the tidal amplitude $(\mathbf{A}, \mathbf{B})$ and travel time $(\mathbf{C}-\mathbf{F})$ only along the South Branches and Upper Reach on 1-2, 8-9 March 2002, compared to observations (symbols).

Passage and the South Passage, where the tidal energy from two channels is combined. This effect was also demonstrated in the Fly River Estuary in Papua New Guinea (King and Wolanski, 1996). Because there is no observation available in this reach, further work is required to confirm this effect. At the junction of the North Channel and the South Channel, this effect is not clear, which may be due to the parallel channels. If we continue the computation for the South Branch using separate topography of the North Channel and the South
Channel after their junction, the computed results fit the measurements well before a point about $90 \mathrm{~km}$ from the mouth, particularly when it fits well at the intersection point of the North Channel and the South Channel (Fig. 7). The Nanmengang station $(81 \mathrm{~km})$ is located at the north bank of the South Branch following the North Channel, and the Yanglin station $(89 \mathrm{~km})$ is situated at the south bank following the South Channel (Figs. 1 and 7). Probably the parallel channels of the North Channel and the South Channel and the similar width 


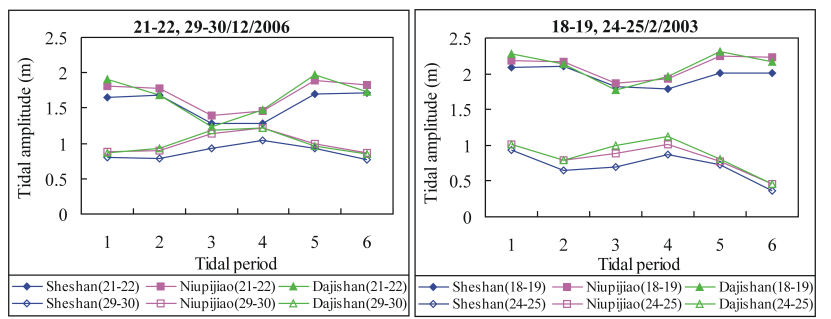

Fig. 6. Tidal amplitudes from tidal table at Sheshan, Niupijiao and Dajishan stations (outside the estuary).

after their junction until $90 \mathrm{~km}$ (Fig. 1), permit the tidal dynamics of the two channels to function separately, which results in the relatively high tidal amplitude at the north bank and lower value at the south bank in this reach following the amplification in the North Channel and the damping in the South Channel.

\subsection{Tidal propagation}

The tidal wave celerity also depends on the imbalance between convergence and friction, with a close relation to tidal damping or amplification (Savenije, 2005). For the North Branch, the tidal wave travels much faster in the lower reach than the upper reach, corresponding with amplification and damping, respectively. Particularly in the lower reach near the mouth, the tidal travel time is almost zero indicating an apparently standing wave. This is in accordance with the tidal amplification and strong convergence, which can lead to a near standing wave in short estuaries (Savenije, 2005). For the South Branches near the mouth, the tidal wave travels faster in the North Passage, which agrees with its small storage width ratio $r_{\mathrm{s}}$ and higher water depth resulting from bank fixation and dredging of the deep-water shipping channel. Furthermore, the higher celerity in the upper reach of the North Channel than in the South Channel is due to the large Manning-Strickler friction factor $K$ and small storage width ratio $r_{\mathrm{s}}$ in the North Channel, corresponding with its slight amplification. At the two junctions, junction 1 and junction 2, the tidal wave in the North Passage and the North Channel seems to "wait" for the wave in the South Passage and the South Channel, respectively, taking time to fill the storage before the joint wave proceeds.

\subsection{Phase lag, estuary shape and friction}

The phase lag $\varepsilon$ is a crucial parameter in tidal hydraulics, which can be used to classify the type of tidal wave, while the estuary shape number $\gamma$ is the main indicator for estuary shape. Figure 8 presents the diagram for the phase lag $\varepsilon$ in different channels, as a function of the estuary shape number $\gamma$ and friction number $\chi$, from which the characteristics of channels can be identified. The lower reach of the North Branch has the largest estuary shape number and a very small

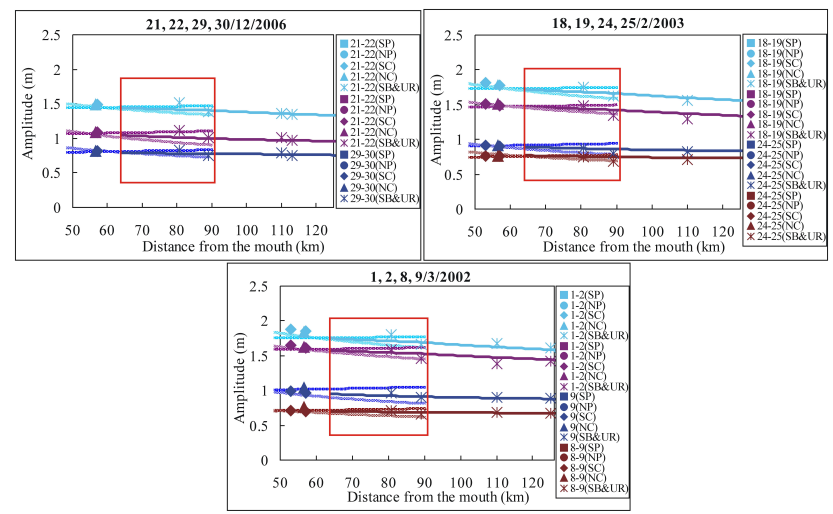

Fig. 7. Computed tidal amplitude for the South Branch after the junction of the North Channel and the South Channel $(64 \mathrm{~km})$ until $90 \mathrm{~km}$ (inside the rectangle frame), using separate topography of these two channels.

phase lag, indicating its marine character with strong convergence. The upper reaches of the South Channel and the North Channel, the South Branch and Upper Reach, all have a very small estuary shape number $\gamma$ and high phase lag, which suggest their riverine character with long convergence length. The South Passage, the North Passage, the lower reaches of the South Channel and North Channel, and the upper reach of the North Branch all lie in between with a moderate estuary shape number and phase lag, which imply that they receive moderate influence both from the sea and river. Of these, the South Passage, the North Passage, the lower reach of the South Channel, and the upper part of the North Branch are all situated around the transition point $\gamma=1.5$ where the lines for different values of $\chi$ cross, the phase lag is insensitive to friction. For $\gamma<1.5$ the phase lag decreases with friction, while for $\gamma>1.5$ it increases with friction. The lower reach of the North Branch apart from the first reach $0-5 \mathrm{~km}$, belongs to the latter situation, whereas other channels belong to the former situation. In the first reach of the North Branch $0-5 \mathrm{~km}$, the estuary shape number is very large more than 8 and $\varepsilon$ is almost 0 which suggests the apparently standing wave without dependence on friction. In other channels and reaches, $0<\varepsilon<\frac{\pi}{2}$ indicates a mixed tidal wave (Savenije, 2005). In the reach upstream from $5 \mathrm{~km}$ in the North Branch with an estuary shape number larger than 2 , which is critical convergence, the very small $\varepsilon$ indicates an approximately standing wave.

Additionally, most reaches of the channels in the Yangtze Estuary lie close to the line of an ideal estuary (the line with dots) where friction and convergence cancel out, with not much damping or amplification. Here, we can also distinguish the amplified channels below the line of the ideal estuary for high $\gamma$ (or marine channels) such as the lower reach of the North Branch, and above the line for small $\gamma$ (or riverine channels) such as the upper reach of the North Channel. It is the reverse for the damped channels. 
Table 2. Difference of the computed tidal amplitude and travel time at two junctions between two approaches.

\begin{tabular}{|c|c|c|c|c|c|c|c|c|c|c|c|c|}
\hline \multirow{2}{*}{ Date } & \multicolumn{6}{|c|}{ junction 1 (North Passage and South Passage) } & \multicolumn{6}{|c|}{ junction 2 (North Channel and South channel) } \\
\hline & $A-1$ & $A-2$ & $t \mathrm{LW}-1$ & $t \mathrm{HW}-1$ & $t \mathrm{LW}-2$ & $t \mathrm{HW}-2$ & $A-1$ & $A-2$ & $t \mathrm{LW}-1$ & $t \mathrm{HW}-1$ & $t \mathrm{LW}-2$ & $t \mathrm{HW}-2$ \\
\hline 21-22 Dec 2006 & 1.58 & 1.59 & 119.62 & 71.87 & 119.15 & 71.41 & 1.45 & 1.44 & 171.34 & 108.34 & 191.14 & 117.97 \\
\hline 21-22 Dec 2006 & 1.22 & 1.22 & 109.40 & 73.64 & 109.12 & 73.33 & 1.05 & 1.06 & 174.14 & 118.80 & 198.53 & 131.54 \\
\hline 29-30 Dec 2006 & 1.09 & 1.08 & 102.02 & 72.69 & 102.05 & 72.62 & 0.94 & 0.94 & 166.43 & 119.03 & 192.29 & 133.27 \\
\hline 29-30 Dec 2006 & 0.93 & 0.93 & 94.29 & 71.44 & 94.66 & 71.62 & 0.81 & 0.82 & 158.84 & 119.33 & 183.54 & 133.97 \\
\hline 18-19 Feb 2003 & 1.92 & 1.92 & 126.91 & 69.82 & 126.62 & 69.28 & 1.72 & 1.72 & 179.68 & 105.11 & 200.77 & 114.27 \\
\hline 18-19 Feb 2003 & 1.62 & 1.63 & 120.45 & 71.65 & 119.99 & 71.18 & 1.47 & 1.47 & 172.16 & 108.00 & 192.19 & 117.60 \\
\hline 24-25 Feb 2003 & 1.02 & 1.02 & 98.60 & 72.13 & 98.80 & 72.21 & 0.90 & 0.89 & 163.73 & 119.07 & 189.21 & 133.69 \\
\hline 24-25 Feb 2003 & 0.88 & 0.88 & 92.11 & 70.94 & 92.40 & 71.25 & 0.76 & 0.77 & 156.25 & 119.46 & 180.40 & 134.37 \\
\hline
\end{tabular}

Note: $A$ - tidal amplitude, $t \mathrm{LW}$ - tidal travel time at low water, $t \mathrm{HW}$ - tidal travel time at high water; 1 indicating approach 1,2 indicating approach 2.

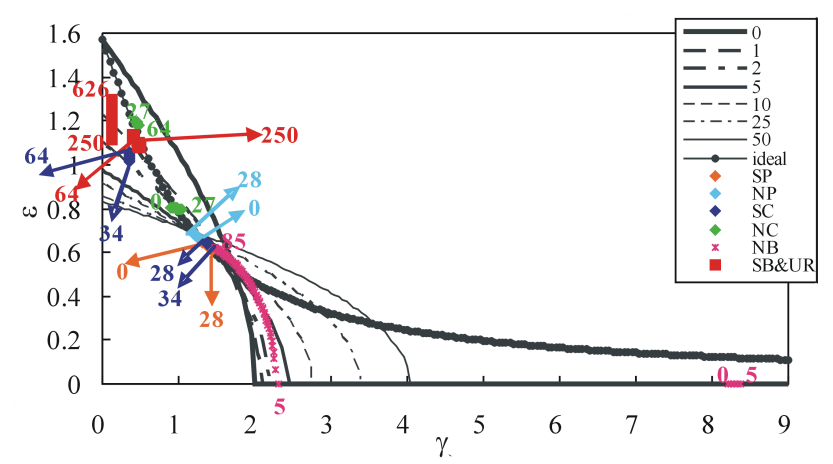

Fig. 8. Positioning of the Yangtze Estuary (NB-North Branch) in the phase lag diagram, the numbers at inflection points indicating the distance from the estuary mouth (in kilometres), the same as Figs. 3-5. The background shows lines with different values of the friction number $\chi$. The drawn line with dots represents the ideal estuary.

\section{4 "Entity" behaviour of the branched estuary}

Based on the assumption that the branched estuary system functions as an entity, the computations for the South Channel and the South Branch can be carried out by means of a combined approach (approach 2) as well. Computations begin from the mouth using the combined topographies. The input of tidal amplitude at the mouth $\eta_{0}$ is the weighted average of the corresponding separate channels, whose crosssectional areas at the mouth are taken as the weight. For the South Channel, topography of the Combined South Channel is used, and the tidal amplitude at the mouth $\eta_{0}$ is the weighted average of the North Passage and the South Passage. For the South Branch, topography of the Combined South Branch is used, and the tidal amplitude at the mouth $\eta_{0}$ is the weighted average of the Combined South Channel and the North Channel, or the weighted average of the South Passage, the North Passage, and the North Channel.

The computed tidal amplitude and travel time for two junctions by means of the two approaches are presented in Ta- ble 2. The approach introduced in Sect. 4.2 is called approach 1. For junction 1 between the North Passage and the South Passage, the computed values using approach 2 are all very close to approach 1 . For junction 2 between the North Channel and the South Channel, the computed tidal amplitudes using the two approaches are almost the same as well. However, the computed tidal travel time using approach 2 is larger than approach 1 by $23 \mathrm{~min}$ at low water and $12 \mathrm{~min}$ at high water on average, which is probably due to the error of determination of the combined topography. These underline the assumption that the branched estuary system functions as an entity for the tidal dynamics, similar to what was concluded for salt intrusion by Nguyen and Savenije (2006), Nguyen et al. (2008), and Zhang et al. (2011).

The Manning-Strickler friction factor $K$ and storage width ratio $r_{\mathrm{s}}$ are key calibration parameters of the model. It can be seen from Table 1 that the values $K$ and $r_{\mathrm{s}}$ of the combined channels are basically the weighted average of the corresponding separate channels, using the cross-sectional areas as the weights. For example, $0-33 \mathrm{~km}$ of the Combined South Channel corresponds with the North Passage and the South Passage, and 34-64 km of the Combined South Branch corresponds with $40-70 \mathrm{~km}$ of the South Channel and $18-53 \mathrm{~km}$ of the North Channel. This behaviour also suggests that the branched estuary system functions as an entity.

\subsection{Uncertainty and limitation of the model}

In this study, the model performs well for the Yangtze Estuary, which indicates that this simple analytical model for single-channel alluvial estuary can describe the tidal dynamics in a branched estuary as well. However, there are several uncertainties and limitations of parameters of the model.

Firstly, the Manning-Strickler friction factor $K$ and storage width ratio $r_{\mathrm{s}}$ are usually obtained by calibration. Because they are related to many factors, there is uncertainty in the determination of these parameters. Additionally, there is a limit to the accuracy that can be obtained for the depth near the estuary mouth. Therefore, although the values we obtain accord with the values in previous research, they 
require more measurements and more accurate topography to be improved.

Secondly, there are uncertainties about the tidal average cross-sectional depth $\bar{h}$. On the one hand, there is uncertainty in the determination of the average depth over the crosssection, particularly when there is a shallow part or deep part. Longitudinally if there is a long reach with a curve fitted depth much lower or higher than the measurements, it is better to modify the depth in the model using the measurements. In this study, we modify the depths between 130 and $250 \mathrm{~km}$ where the curve fitted values are much higher than the data (Fig. 2f), then as a result, the model results are better. For the combined channels used in approach 2 , the uncertainty may be larger because the lengths of the corresponding separate channels are different, which probably causes the larger tidal travel time at junction 2. On the other hand, the $\bar{h}$ in Savenije's model is the average depth at mean sea level, whereas in this study it is the tidal average depth for different tidal ranges (the tidal average depth varies with the tidal amplitude). In this analysis, we take account of this difference. We find that the results are much better if we use the actual tidal average depth for different tidal ranges, particularly when the tidal range is very high or low. This procedure requires further confirmation based on more observations and more accurate bathymetry.

Thirdly, one assumption of the model is the partially to well mixing characteristic of the estuary. The North Branch of the Yangtze Estuary is a marine well-mixed channel. The South Branches are the more riverine partially-mixed channels in which well-mixed situations also occur during the dry season (Zhang et al., 2011). During the flood season the influence from river discharge undoubtedly is larger, which likely induces higher computed values than the actual ones. Because we have no data during the flood season, further work is required to include the effect of river discharge in the model.

\section{Conclusions}

In this study, an analytical model for tidal dynamics has been applied for the first time to the Yangtze Estuary, a large and typical branched estuary. The results indicate that this simple model originally derived for single-channel alluvial estuaries can very well describe the tidal propagation in a branched estuary as well, particularly for the lower part. The satisfactory results for the South Channel and the South Branch using both the individual topographies and the combined topographies confirm that a branched estuary system functions as an entity. However, the model requires more measurements and more accurate bathymetry to improve and confirm the parameters used.

\section{Appendix A}

\section{Assumptions of the model}

The assumptions made for the model development are as follows:

1. The spatial variation of the cross-sectional area along the estuary can be described by an exponential function, as is the case in alluvial estuaries.

The shape of alluvial estuaries can be described by the following exponential functions (Savenije, 2005):

$A=A_{0} \exp \left(-x / a_{i}\right) \quad(i=1)$,

$A=A_{(i-1)} \exp \left(-\left(x-x_{(i-1)}\right) / a_{i}\right)(i>1)$

$B=B_{0} \exp \left(-x / b_{i}\right) \quad(i=1)$,

$B=B_{(i-1)} \exp \left(-\left(x-x_{(i-1)}\right) / b_{i}\right) \quad(i>1)$

$h=h_{0} \exp \left(x\left(a_{i}-b_{i}\right) / a_{i} b_{i}\right) \quad(i=1)$,

$h=h_{(i-1)} \exp \left(\left(x-x_{(i-1)}\right)\left(a_{i}-b_{i}\right) / a_{i} b_{i}\right) \quad(i>1)$

where $A, B$ and $h$ are the cross-sectional area, width and depth at location $x$ from the mouth, respectively; $A_{0}, B_{0}$ and $h_{0}$ are the area, width and depth at the mouth. In estuaries where the geometry of channels cannot be described by a single exponential function, multiple reaches can be used, where $i$ represents the reach number ( $i=1,2,3 \ldots$, beginning from the mouth), $a_{i}$ and $b_{i}$ are the area and width convergence length for reach $i, x_{(i-1)}$ is the inflection point, and $A_{(i-1)}, B_{(i-1)}$, and $h_{(i-1)}$ are the cross-sectional area, width and depth at the inflection point.

2. The ratio of the tidal amplitude to depth is less than unity.

3. The freshwater discharge is small compared to the amplitude of the tidal discharge. Although during a flood situation or in the most upstream part of an estuary this may not always be the case, in exponentially shaped estuaries this is not a restrictive assumption.

4. The Froude number is small, which is essentially the same as assumption 2, but less restrictive. The Froude number is generally smaller than the amplitude to depth ratio.

5. The tidal wave can be described by a simple harmonic function. If the tidal amplitude to depth ratio and the freshwater to tidal discharge ratio are small, then the tidal wave is not much deformed by nonlinear effects, but it is unavoidable that as the wave travels further inland, the wave deforms, resulting in a longer ebb and 
shorter flood duration. Implicitly this assumption is a linearisation assumption, but it is less restrictive than the linearisation of the friction term.

6. The width to depth ratio should be large $(B / h \gg 1)$, and the storage width ratio (the ratio of the storage width (including tidal flats) to the stream width) should be modest $\left(r_{\mathrm{s}}<2\right)$. This is a nonrestrictive assumption which is not really important since it only affects the second term of Eq. (1) which scales at the Froude number, and moreover alluvial estuaries have a large width to depth ratio.

7. The salt intrusion is partially or well mixed, which relates to assumption 3, while it is not a restrictive assumption.

8. Tidal damping is modest. It implies that the length scale of the damping/amplification process is much longer than the distance travelled by a water particle (the tidal excursion $E$ ). This assumption is also not restrictive in alluvial estuaries, as is shown empirically (Savenije, 2005).

9. The wave celerity and the phase lag between HW and HWS are constant over an estuary reach, or at least a small reach after which the equations can be solved in multiple reaches in which they are considered constant. This assumption is fully justified in an ideal estuary where there is no tidal damping or amplification, but it is acceptable if assumption 8 is adhered to.

Of the 9 assumptions, assumptions (1-3) are the basic assumptions, the others are derivatives of these three basic assumptions, and assumption 9 is only required for the celerity equation. It can be seen that for alluvial estuaries most assumptions are not restrictive particularly for the downstream part.

Acknowledgements. This study was supported by the National Natural Science Foundation of China (Grant No. 40701182) as well as the State Key Laboratory of Estuarine and Coastal Research (SKLEC-2012KYYW06). Authors acknowledge the Bureau of Hydrological and Water Resources Survey of the Yangtze Estuary, Shanghai Hydrological Administration, and Marine Safety Administration of Shanghai for kindly providing the tidal measurements data.

Edited by: A. D. Reeves

\section{References}

Chen, J. Y. and Chen, S. L.: Variation in ecology and environment in the Yangtze Estuary and suggestion on hanessing the estuary, Water Resources and Hydropower Engineering, 34, 19-25, 2003 (in Chinese).
Dronkers, J. J.: Tidal Computations in Rivers and Coastal Waters, North Holland Publishing Company, Amsterdam, 518 pp., 1964.

Dyer, K. R.: Estuaries: a physical introduction, John Wiley \& Sons, Aberdeen, London, 140 pp., 1973.

Friedrichs, C. T. and Aubrey, D. G.: Tidal propagation in strongly convergent channels, J. Geophys. Res., 99, 3321-3336, 1994.

Friedrichs, C. T. and Madsen, O. S.: Nonlinear Diffusion of the Tidal Signal in Frictionally Dominated Embayments, J. Geophys. Res., 97, 5637-5650, 1992.

Harleman, D. R. F.: Tidal dynamics in estuaries, part II: Real estuaries, in: Estuary and Coastline Hydrodynamics, edited by: Ippen, A. T., McGraw-Hill, New York, 493-545, 1966.

Henderson, F. M.: Open channel flow, Macmillan, New York, 522 pp., 1966.

Horrevoets, A. C., Savenije, H. H. G., Schuurman, J. N., and Graas, S.: The influence of river discharge on tidal damping in alluvial estuaries, J. Hydrol., 294, 213-228, 2004.

Ippen, A. T.: Tidal dynamics in estuaries, part I: Estuaries of rectangular section, in: Estuary and Coastline Hydrodynamics, edited by: Ippen, A. T., McGraw-Hill, New York, 493-522, 1966.

Jay, D. A.: Green's Law revisited: Tidal long-wave propagation in channels with strong topography, J. Geophys. Res., 96, 2058520598, 1991.

King, B. and Wolanski, E.: Bottom friction reduction in turbid estuaries, in: Mixing in estuaries and coastal seas Coastal and Estuarine studies, edited by: Pattiaratchi, C., American Geophysical Union, Florida Avenue, NW, Washington, 325-337, 1996.

Kong, L. S., Wang, W., Gu, F. F., Qi, D. M., and Zhao, D. Z.: Research on channel regulation scheme of Baimaosha reach in the Yangtze Estuary, Journal of Waterway and Harbor, 31, 379-383, 2010 (in Chinese).

Langbein, W. B.: The hydraulic geometry of a shallow estuary, Bulletin of International Association of Scientific Hydrology, 8, 8494, 1963.

Lanzoni, S. and Seminara, G.: On tide propagation in convergent estuaries, J. Geophys. Res., 103, 30793-30812, 1998.

Limerinos, J. T.: Relation of the Manning coefficient to measured bed roughness in stable natural channels, in: Geological survey research, United States Department of the Interior, United States Printing Office, Washington, D215-221, 1969.

Liu, S. G., Yu, W. W., Kuang, C. P., and Sun, B.: Preliminary Prediction on Recent Topography Evolution of Nanhui Tidal Flat in Yangtze Estuary due to Three Gorges Project, Journal of Tongji University (natural science), 38, 679-684, 2010 (in Chinese).

Liu, X. C., Lu, Y. J., Pan, L. H., and Wu, J. W.: Tidal current numerical simulating and water exchange research in Yangtze Estuary and Hangzhou Bay, J. Hydrodyn., 21, 171-180, 2006 (in Chinese).

Nguyen, A. D. and Savenije, H. H. G.: Salt intrusion in multichannel estuaries: a case study in the Mekong Delta, Vietnam, Hydrol. Earth Syst. Sci., 10, 743-754, doi:10.5194/hess-10-7432006, 2006.

Nguyen, A. D., Savenije, H. H. G., Pham, D. N., and Tang, D. T.: Tidal wave propagation in the branches of a multi-channel estuary: the Mekong Delta case, in: Proceedings of the 4th international conference PDCE 2007, edited by: Penchev, V. and Verhagen, H. J., Varna, Bulgaria, 239-248, 2007.

Nguyen, A. D., Savenije, H. H. G., Pham, D. N., and Tang, D. T.: Using salt intrusion measurements to determine the freshwater 
discharge distribution over the branches of a multi-channel estuary: The Mekong Delta case, Estuar. Coast. Shelf S., 77, 433445, 2008.

Prandle, D.: Relationships between tidal dynamics and bathymetry in strongly convergent estuaries, J. Phys. Oceanogr., 33, 27382750, 2003.

Prandle, D. and Rahman, M.: Tidal response in estuaries, J. Phys. Oceanogr., 10, 1552-1573, 1980.

Savenije, H. H. G.: Analytical expression for tidal damping in alluvial estuaries, J. Hydraul. Eng., 124, 615-618, 1998.

Savenije, H. H. G.: A simple analytical expression to describe tidal damping or amplification, J. Hydrol., 243, 205-215, 2001.

Savenije, H. H. G.: Salinity and Tides in Alluvial Estuaries, Elsevier, Amsterdam, 197 pp., 2005.

Savenije, H. H. G. and Veling, E. J. M.: The relation between tidal damping and wave celerity in estuaries, J. Geophys. Res., 110, C04007, doi:10.1029/2004JC002278, 2005.

Savenije, H. H. G., Toffolon, M., Haas, J., and Veling, E. J. M.: Analytical description of tidal dynamics in convergent estuaries, J. Geophys. Res., 113, C10025, doi:10.1029/2007JC004408, 2008.

Shen, H. T. and Li, J. F.: Water and sediment transport in the Changjiang Estuary, China Ocean Press, Beijing, 222 pp., 2011 (in Chinese).

Shen, H. T., Gu, G. C., and Li, J. F.: Characteristics of tidal wave and their influence on revolution of the channels in the Changjiang Estuary, in: Processes of dynamics and geomorphology of the Changjiang Estuary, edited by: Chen, J. Y., Shen, H. T., and Yun, C. X., Shanghai Scientific and Technical Publishers, Shanghai, 73-79, 1988 (in Chinese).

Shen, H. T., Mao, Z. C., and Zhu, J. R.: Saltwater Intrusion in the Changjiang Estuary, China Ocean Press, Beijing, 175 pp., 2003 (in Chinese).

Shen, J., Shen, H. T., Pan, D. A., and Xiao, C. Y.: Analysis of transport mechanism of water and suspend sediment in the turbidity maximum of the Changjiang Estuary, Acta Geographica Sinica, 50, 411-420, 1995 (in Chinese).

Shi, Z., Zhou, H. J., Eittreim, S. L., and Winterwerp, J. C.: Settling velocities of fine suspended particles in the Changjiang Estuary, China, J. Asian Earth Sci., 22, 245-251, 2003.
Tan, P. L. and Wang, H. Y.: Function of Three Gorges Project against Salty-tide Invasion in Yangtze Mouth, China Three Gorges Construction, 5, 29-31, 2004 (in Chinese).

Toffolon, M. and Savenije, H. H. G.: Revisiting linearized one-dimensional tidal propagation, J. Geophys. Res., 116, C07007, doi:10.1029/2010JC006616, 2011.

Wang, D. G., Chen, X. J., and Yang, Y. Y.: Finite difference simulation of horizontally 2-D flow field of ChangJiang Estuary, Journal of Hohai University, 15, 34-46, 1987 (in Chinese).

Wang, Z. B.: Some considerations on mathematical modeling of morphological processes in tidal basins, in: Dynamics and Exchanges in Estuaries and the Coastal Zone, Coastal and Estuarine Studies 40, edited by: Prandle, D., American Geophysical Union, Washington DC, New York, 467-480, 1992.

Wolanski, E., Gibbs, R. J., Mazda, Y., Mehta, A., and King, B.: The role of turbulence in the settling of mud flocs, J. Coastal Res., 8, 35-46, 1992.

Yang, L. H., Zhu, J. R., and Zhu, S. X.: 3-D numerical simulation of tide and tidal current fields in the Changjiang Estuary, Hangzhou Bay and their adjacent sea, Journal of East China Normal University (Natural Science), 3, 74-84, 2001 (in Chinese).

Yu, F. X., Song, Z. Y., and Li, R. J.: A 3-D hydrodynamical model for tidal current field of the Yangtze River Estuary, Transactions of Oceanology and Limnology, 3, 14-23, 2003 (in Chinese).

Yu, W. W., Yang, H. L., Liu, S. G., and Qi, D. M.: Impact of the improvement project of Deep-Water Channel on flow field of the Yangtze Estuary, J. Hydrodyn., 22, 709-715, 2007 (in Chinese).

Zhang, E. F., Savenije, H. H. G., Wu, H., Kong, Y. Z., and Zhu, J. R.: Analytical solution for salt intrusion in the Yangtze Estuary, China, Estuar. Coast. Shelf S., 91, 492-501, 2011.

Zhou, H. J. and Wu, S. R.: Numerical modeling of suspended sediment transport in the Changjiang Estuary, in: Proceedings of the International Symposium: waves-physical and numerical modeling, edited by: Isaacson, M. and Quick, M., University of British Columbia, Vancouver, 1636-1644, 1994. 